\title{
POLARIMETRIC SAR DATA FROM SENTINEL-1A APPLIED TO EARLY CROP CLASSIFICATION
}

\author{
L. V. Oldoni ${ }^{1}$ V. H. R. Prudente ${ }^{1,2}$, J. M. F. S. Diniz ${ }^{1}$, N. C. Wiederkehr ${ }^{1}$, I. D. Sanches ${ }^{1}$, F. F. Gama ${ }^{1}$ \\ ${ }^{1}$ National Institute for Space Research (INPE), Av. dos Astronautas, 1758, Jd da Granja, 12227-010, São José dos Campos, SP, \\ Brazil - (lucas.oldoni, victor.prudente, juliana.diniz, natalia.wiederkehr, idea.sanches, fabio.furlan)@inpe.br \\ ${ }^{2}$ Department of Geographical Sciences, University of Maryland, College Park MD 20742, USA
}

Commission III, WG III/10

KEY WORDS: Agriculture monitoring, Remote Sensing, Microwave, Soybean, Early classification, Machine learning

\begin{abstract}
:
This paper aims to map crops in two Brazilian municipalities, Luís Eduardo Magalhães (LEM) and Campo Verde, using dualpolarimetric Sentinel-1A images. The specific objectives were: (1) to evaluate the accuracy gain in the crop classification using Sentinel-1A multitemporal data backscatter coefficients and ratio $\left(\sigma^{0} \mathrm{VH}, \sigma^{0} \mathrm{VV}\right.$ and, $\sigma^{0} \mathrm{VH} / \sigma^{0} \mathrm{VV}$, denominate BS group) in comparison to the addition of polarimetric attributes $\left(\sigma^{0} \mathrm{VH}, \sigma^{0} \mathrm{VV}, \sigma^{0} \mathrm{VH} / \sigma^{0} \mathrm{VV}, \mathrm{H}\right.$, and $\alpha$, denominate BP group) and; (2) to assess the accuracy gain in the earliest crop classification, creating new scenarios with the addition of the new SAR data together with the previous images for each date and group (BS and BP) during the crop development. For BS and BP groups, 13 e 10 scenarios were analyzed in LEM and Campo Verde, respectively. For the classification process, we used the Random Forest (RF) algorithm. In the LEM site, the best results for BS and BP groups were equivalent (overall accuracy: $\sim 82 \%$ ), while for the Campo Verde site, the classification accuracy for the BP group (overall accuracy: $\sim 80 \%$ ) was $2 \%$ higher than the BS group. The addition of new images during the crop development period increased the earliest crop classification overall accuracy, stabilizing from mid-February in LEM and mid-December in Campo Verde, after 10 and 8 images, respectively. After these periods, the gain in classification accuracy was small with the addition of new images. In general, our results suggest the backscattering coefficients and polarimetric attributes extracted from the Sentinel-1A imagery exhibited a great performance to discriminate croplands.
\end{abstract}

\section{INTRODUCTION}

Brazil occupies the first positions in the world ranking of agricultural production of soybeans, corn, coffee, cotton, among others (FAOSTAT, 2020). Thereby, knowing where and which crops are present in the fields is useful in regional and global scales (Kussul et al., 2016; McNairn et al., 2014). This information is crucial for crop management, food security assurance and agricultural policy design (Arias et al., 2020; McNairn et al., 2014).

Crop classification is one of the most important agricultural applications of Remote Sensing (RS) (Atzberger, 2013). RS provides synoptic character and data acquisition promptness highlighted as a technique to map and monitor the crops throughout their lifecycle (Oldoni et al., 2019a; Prudente et al., 2019a; Veloso et al., 2017). Moreover, early or in-season crop information allows critical support for timely crop yield and production estimates (You and Dong, 2020).

While RS data are essential for agricultural mapping and monitoring, to provide accurate crop information is a challenging step due to the high spatio-temporal dynamics (Denize et al., 2019; Hütt and Waldhoff, 2018). Besides, optical cloud-free image acquisition is a challenge too (Whitcraft et al., 2015b; Wulder et al., 2015). Because of these factors, some regions might have only a few cloud-free optical RS data available during the crops vegetative cycle, especially at the end of flowering and beginning of plant senescence (Eberhardt et al., 2016; Whitcraft et al., 2015a). Thus, the use of optical RS data is even more sensible in tropical, subtropical, and northern regions (Evans and Costa, 2013), where the cloud cover frequency is higher.

Therefore, to overcome this cloud limitation, the Synthetic Aperture Radar (SAR), can be a useful alternative. SAR data collection can be performed under almost all-weather conditions, independently of lighting conditions and are little affected by atmospheric and cloud cover (Arias et al., 2020; Harfenmeister et al., 2019). For this reason, it is possible to obtain a dense temporal series of useful SAR data, even in areas with high cloud cover, such as tropical regions.

However, SAR data interpretation is complex, with many factors influencing the interaction between plant and microwave beam. The returned SAR signal is influenced by canopy properties, like dielectric constant (or water content), geometry, orientation, topography and surface roughness, besides by the radar system features, like frequency, polarization, spatial resolution, incident angle, orbit, etc (Harfenmeister et al., 2019; Steele-Dunne et al., 2017).

For example, for the cropland, each radar polarization is more sensitive to certain characteristics of vegetation. In a SAR system, microwave beams vertically (V) polarized are more sensitive to the vertical structure, while the horizontally $(\mathrm{H})$ polarized waves are more sensitive to horizontal structures (Denize et al., 2019; McNairn and Brisco, 2004). The copolarized $\mathrm{HH}$ waves demonstrate more sensitivity to surface scattering, while, the cross-polarization, $\mathrm{VH}$, and $\mathrm{HV}$, are more sensitive to volume dispersion (Denize et al., 2019; Veloso et al., 2017).

Moreover, radars operating at longer wavelengths ( $\mathrm{L}$ and $\mathrm{P}$ bands) penetrate inside the canopy, while those of shorter wavelengths ( $\mathrm{C}$ and $\mathrm{X}$ bands) interact with the upper layers of the canopy. These factors determine the radar backscatter from vegetation and they are crop-specific and vary as crop phenology changes, thus, there is significant potential for the use of SAR in agricultural applications, like classification, crop monitoring, and soil/vegetation moisture monitoring (McNairn and Brisco, 2004; Steele-Dunne et al., 2017). 
Besides the backscattering, information can be extracted from SAR data using the Polarimetric SAR (PolSAR) technique. This method uses information about the amplitude and phase of the signals reflected in different polarizations and stored in a complex vector structure (Ulaby, Fawwaz and Elachi, 1990). From the PolSAR technique, it is possible to use the target decomposition theorems (Cloude and Pottier, 1996). The decomposition theorems separate the scattering mechanisms of different natures, making it possible to infer the physical properties of the targets. It also can help improve segmentation, classification, target detection, and pattern recognition.

The H/ $\alpha$ decomposition (Cloude and Pottier, 1996) allows obtaining the polarimetric attributes of entropy $(\mathrm{H})$ and alpha angle $(\alpha)$. Entropy indicates the number of dominant scattering mechanisms, making it possible to assess the degree of randomness of the scattering process (Cloude and Pottier, 1996). The $\mathrm{H}$ polarimetric attribute ranges from 0 to 1 . Low $\mathrm{H}$ values $(\sim 0)$ indicate weak polarization, suggesting the presence of a single scattering mechanism. On the other hand, high $\mathrm{H}$ values $(\sim 1)$ indicate the presence of at least three targets that also contribute to depolarize electromagnetic waves. The alpha angle identifies the type of scattering, which varies from $\alpha=0^{\circ}$ characterized as superficial scattering, $\alpha=45^{\circ}$ volumetric scattering and, $\alpha=90^{\circ}$ double-bounce scattering (Cloude and Pottier, 1996).

In this sense, free polarimetric SAR data from Sentinel-1A and 1B satellites, which are available by European Space Agency (ESA), represent a new opportunity to investigate agricultural monitoring methods based on dense SAR time series (Denize et al., 2019), since Sentinel-1 has a high temporal resolution (12 days Sentinel-1A and, 06 days when considering Sentinel-1A and $1 \mathrm{~B}$ ) and a spatial resolution around $10 \mathrm{~m}$ (ranging from 5 to $40 \mathrm{~m}$, depending on the acquisition mode). In this context, two specific goals were defined: (1) to evaluate the accuracy gain in crop classification by Random Forest algorithm using Sentinel1A multitemporal data backscatter coefficients $\left(\sigma^{0}\right)$ in the polarizations $\mathrm{VH}\left(\sigma^{0} \mathrm{VH}\right), \mathrm{VV}\left(\sigma^{0} \mathrm{VV}\right)$ and the ratio between them $\left(\sigma^{0} \mathrm{VH} / \sigma^{0} \mathrm{VV}\right)$, in comparison to the addition of polarimetric attributes $(\mathrm{H}$ and $\alpha)$, in two test sites in Brazil and; (2) to assess the accuracy gain of the earliest crop classification with the integration of additional SAR dates in the polarimetric attributes and backscatter coefficients.

\section{METHODOLOGY}

\subsection{Study area}

Two municipalities were selected in Brazil as test sites for this study (Figure 1). One is Luís Eduardo Magalhães (LEM), located in western Bahia state, and the other is Campo Verde, located in the southeastern of the Mato Grosso state. Both areas are inserted into the Cerrado biome (Brazilian Savanna).

The LEM central coordinates are $12^{\circ} 05^{\prime} 31^{\prime \prime} \mathrm{S}$ and $45^{\circ} 48^{\prime} 18^{\prime \prime} \mathrm{W}$ (Figure 1a). It comprises an area of $3,940.5 \mathrm{~km}^{2}$, with an altitude of $720 \mathrm{~m}$ and presents tropical wet and dry climate (Aw), according to the Köppen-Geiger classification (Peel et al., 2007). The average annual rainfall is $1,511 \mathrm{~mm}$ and the average temperature is $24.2^{\circ} \mathrm{C}$. This municipality is inserted in the MATOPIBA economic region, which is an important agricultural frontier that comprises parts of Maranhão, Tocantins, Piauí, and Bahia states. The LEM agricultural production is based mainly on soybean $(179,540 \mathrm{ha})$, corn
$(19,136 \mathrm{ha})$, sorghum (14,000 ha), cotton (12,100 ha), and beans $(7,910 \mathrm{ha})$; these numbers correspond to the planted area of each culture in 2018 according to the Municipal Agricultural Production survey (PAM, 2018), held by the Brazilian Institute of Geography and Statistics (IBGE). Due to this agriculture importance, LEM has the 4th higher Gross Domestic Product (GDP), BRL 601,242.05 among Bahia municipalities (IBGE, 2017).
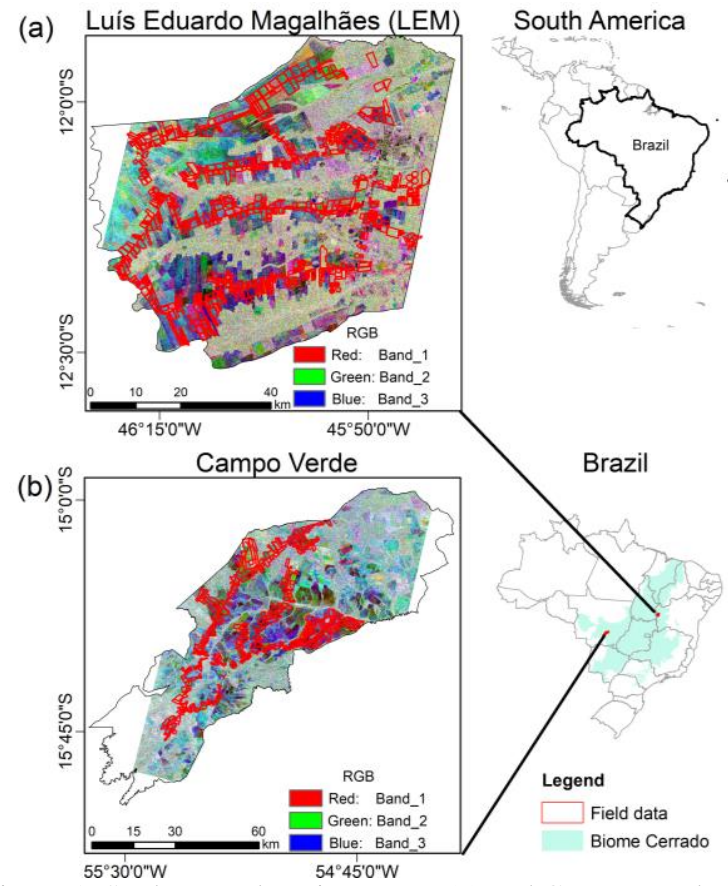

Figure 1. Study areas location: LEM (a) and Campo Verde (b). The images show a RGB composition with Entropy values in three different dates. The red polygons represent the spatial distribution from the LEM and Campo Verde Databases.

The central coordinates of Campo Verde are $15^{\circ} 37^{\prime} 19.4$ " S and $55^{\circ} 10^{\prime} 29.6$ " W (Figure 1b) and correspond an area of 4,794.56 $\mathrm{km}^{2}$. The region is characterized by an average temperature of $22.3^{\circ} \mathrm{C}$, average annual rainfall of $1,726 \mathrm{~mm}$ and Tropical Aw climate, according to the Köppen-Geiger classification (Peel et al., 2007). This municipality has an economic profile based on agribusiness, and according to the PAM survey (PAM, 2018), in 2018 Campo Verde was the 10th Brazilian municipality with the highest value of agricultural production (BRL 1,905,073). The most cultivated crops were soybean $(210,000 \mathrm{ha})$, corn $(88,500$ ha), cotton ( $85000 \mathrm{ha})$, beans ( $3800 \mathrm{ha})$, and sorghum (2,000 ha). Besides, there are also other types of crops, livestock, and forest production (eucalyptus).

In LEM and Campo Verde, two harvests are normally grown in one year. One during the raining season (or wet period), from October until March, that represents the first crop season in the agricultural calendar. The second one occurs in the dry period, from March until August, corresponding to the second crop season.

\subsection{Field Data}

Field reference is essential for remote sensing applications. For the present work, we used two available datasets, the LEM Database (Sanches et al., 2018a) and the Campo Verde Database (Sanches et al., 2018b). These databases provide field references about croplands and other land cover types. For our analysis, 
information regarding the first crop season was selected from both test sites. The data in the databases were collected during fieldworks carried out in LEM, between 14-19 ${ }^{\text {th }}$ March 2018, and in Campo Verde, between 14-18 ${ }^{\text {th }}$ December 2015.

LEM and Campo Verde database have 12 Land Use and Land Cover (LULC) classes, as specified for Sanches et al. (2018a and $2018 b)$. For this work, some classes were grouped due to the legend similarities and others due to the low samples available for the classification process. In this way, 05 classes were considered for LEM: Soybean, Corn, Other Annual Crops - OAC (beans, hay, millet, non-commercial crop, grass), Pasture, and Others (Cerrado, coffee, eucalyptus, conversion area). The number of polygons selected for each of these classes was 419 , 56, 175, 23, and 93, respectively, for Soybeans, Corn, OAC, Pasture, and Other classes. For Campo Verde, we got 04 classes: Soybean, OAC (beans, brachiaria, grass, millet, sorghum, soil, crotalaria, and turfgrass), Pasture, and Others (Cerrado and eucalyptus), with $352,30,48$ and, 79 polygons respectively.

It is important to highlight that Soybean and Corn represent the highest value of agricultural production for both municipalities (PAM, 2018). For this reason, each one was separate in one single class and the other crops were grouped into the OAC class.

\subsection{Sentinel-1A data and pre-processing}

Sentinel-1A images were acquired in IW (Interferometric Wide swath) mode, with a spatial resolution of $5 \mathrm{~m} \times 20 \mathrm{~m}$, dual-pol polarization VH and VV, and Level-1 Single Look Complex (SLC) processing level. The images were downloaded through the Copernicus Open Access Hub, also known as the Sentinels Scientific Data Hub (https://scihub.copernicus.eu/), with an open-source toolbox in a python routine, named SentinelSat (https://github.com/sentinelsat/sentinelsat) (Hu et al., 2018). In total, 13 images were downloaded for LEM (03-11-2017 to 0327-2018, scene T083), and 19 images for Campo Verde (05-102015 to 03-09-2016, 10 images for T090 scene and 09 images for T091 scene). These intervals were used to cover all the first crop season. The images from each scene were pre-processing separately. Only after the pre-process, it was performed the mosaic from the Campo Verde scenes (with the exception of a date that does not require a mosaic).

To pre-process Sentinel-1A data, the following steps were defined (Figure 2a): TOPSAR Split to select only the bursts that covered the study area; Orbit File: to correct the orbit; TOPSAR Deburst: to join the sub-swaths; Multilook: to resample the SAR images by a spatial average, with a window size of $4 \mathrm{x} 1$ pixels (pixel size converted to $14.04 \mathrm{~m}$ by $13.47 \mathrm{~m}$, respectively, in azimuth and range directions). These steps were performed for all polarimetric attributes and backscattering coefficients.

After performing the above mentioned steps (Figure 2a), to obtain the backscattering coefficients $\left(\sigma^{0} \mathrm{VH}\right.$ and $\left.\sigma^{0} \mathrm{VV}\right)$ (Figure $2 b)$, SAR images were filtered with Boxcar Filter with a window size of $7 \times 7$ pixels, to reduce the speckle effect. In sequence, the radiometric calibration step of SAR data was performed. Afterward, terrain correction was applied using the SRTM (Shuttle Radar Topography Mission), this process generated images with a spatial resolution of $14.04 \mathrm{~m}$. Finally, the ratio between $\sigma^{0} \mathrm{VH} / \sigma^{0} \mathrm{VV}$ was calculated.

In turn, to obtain the polarimetric attributes, $\mathrm{H}-\alpha$ polarimetric decomposition was processed (Figure 2c), generating the entropy $(\mathrm{H})$ and alpha angle $(\alpha)$. In sequence, SAR images also were filtered with Boxcar Filter with a window size of $7 \times 7$ pixels, and terrain correction was applied using the SRTM. All the preprocessing steps (Figure 2) were performed using the Sentinel Application Platform (SNAP) 7.0, and python routines.

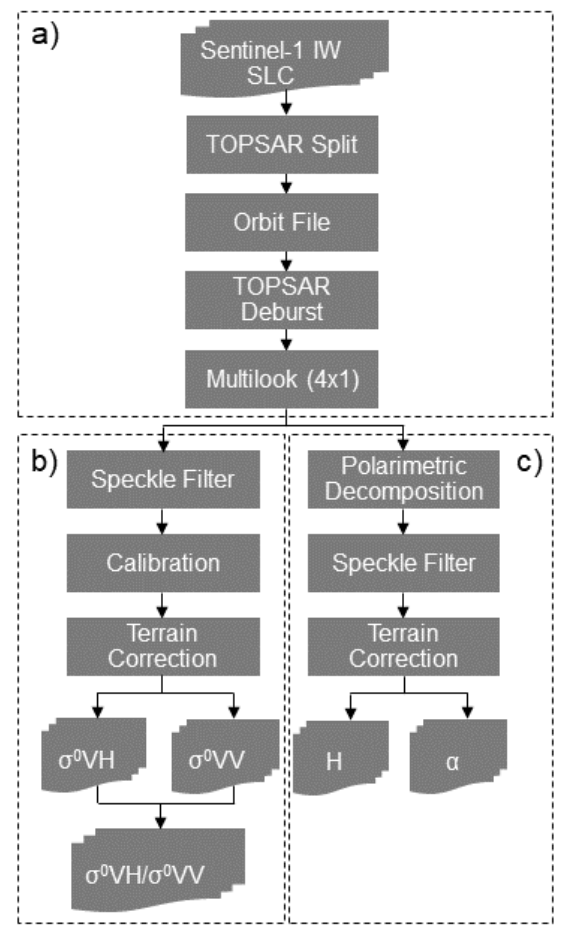

Figure 2 Pre-processing steps for each Sentinel-1 image: (a) pre-processing to both polarimetric attributes and backscattering coefficients; (b) backscattering coefficients; (c) polarimetric attributes.

\subsection{Crops classification scenarios}

Two crop classification groups were defined. The first group is formed by the backscattering coefficients in the polarizations $\mathrm{VH}$ $\left(\sigma^{0} \mathrm{VH}\right)$ and $\mathrm{VV}\left(\sigma^{0} \mathrm{VV}\right)$, and the ratio between them $\left(\sigma^{0} \mathrm{VH} /\right.$ $\sigma^{0} \mathrm{VV}$ ) (Lu et al., 2011), is the group: $\sigma^{0} \mathrm{VH}, \sigma^{0} \mathrm{VV}$, and $\sigma^{0} \mathrm{VH} / \sigma^{0} \mathrm{VV}$, as shown in Figure $2 \mathrm{~b}$. The second group is composed of the backscatter coefficients, ratio (Figure 2b), and the $\mathrm{H}$, and $\alpha$ attributes, derived from the polarimetric decomposition (Figure 2c), being: $\sigma^{0} \mathrm{VH}, \sigma^{0} \mathrm{VV}, \sigma^{0} \mathrm{VH} / \sigma^{0} \mathrm{VV}, \mathrm{H}$ and $\alpha$. The first group was named Backscattering (BS) and the second Backscattering Polarimetric (BP).

For both groups, BS and BP, the accuracy during the period of crop development were simulated. For this, classifications were made considering BS and BP for each date, which included all images from the specific date and previous dates. Thus, a total of 26 classifications scenarios were performed for LEM (13 scenarios to BS group, and others 13 scenarios to BP group), as shown in Figure 3a. For Campo Verde, a total of 20 classifications scenarios were performed (Figure 3b). For the first scenario (scenario 1) in LEM and Campo Verde, 3 attributes were used for BS $\left(\sigma^{0} \mathrm{VH}, \sigma^{0} \mathrm{VV}, \sigma^{0} \mathrm{VH} / \sigma^{0} \mathrm{VV}\right)$, and 5 for BP $\left(\sigma^{0} \mathrm{VH}, \sigma^{0} \mathrm{VV}, \sigma^{0} \mathrm{VH} / \sigma^{0} \mathrm{VV}, \mathrm{H}\right.$ and $\left.\alpha\right)$. On the other hand, in LEM, 39 attributes were used for scenario 13 BS (the 3 attributes of each date $\mathrm{x} 13$ dates), and 65 attributes for scenario $13 \mathrm{BP}$ (the 5 attributes of each date $\times 13$ dates). 

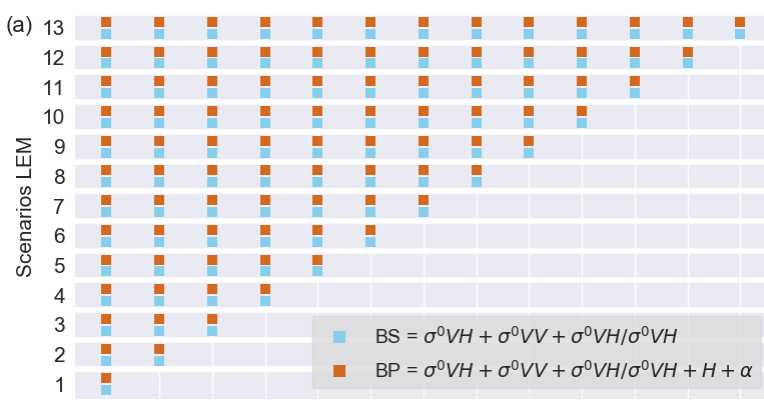

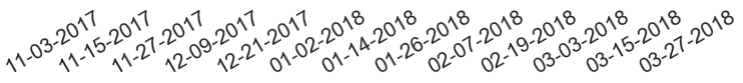

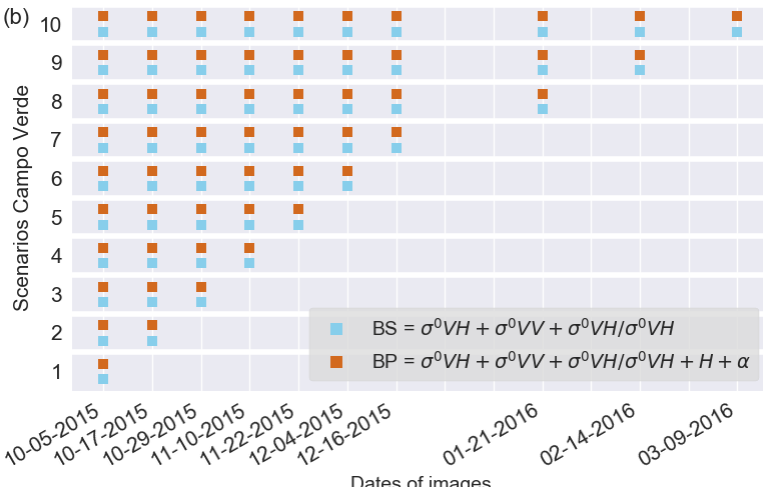

Dates of images

Figure 3. Date of images used in each classification scenarios for LEM (a) and Campo Verde (b): BS (Backscattering coefficients $-\sigma^{0} \mathrm{VH}, \sigma^{0} \mathrm{VV}$, and $\sigma^{0} \mathrm{VH} / \sigma^{0} \mathrm{VV}$ ) and $\mathrm{BP}$

(Backscattering coefficients + Polarimetric attributes $-\sigma^{0} \mathrm{VH}$, $\sigma^{0} \mathrm{VV}, \sigma^{0} \mathrm{VH} / \sigma^{0} \mathrm{VV}, \mathrm{H}$, and $\left.\alpha\right)$

The Random Forest (RF) algorithm was used due to excellent results for crop classifications and high velocity of processing (Breiman, 2001; Du et al., 2015; Pal, 2005; Rodriguez-Galiano et al., 2012). Besides that, RF does not assume a priori statistic distribution, allowing the use of radar data (Furtado et al., 2016). The RF was implemented using the machine learning library for Python, Scikit-Learn (Pedregosa et al., 2011). For each scenario of each group, a stack of data was created and insert to RF for classification.

For training and validation, the cross-validation method was used. $2 / 3$ of the polygons were randomly divided for training and $1 / 3$ for validation in 3 repetitions. Thus, pixels of the same polygons were not used simultaneously for training and validation. To train the RF algorithm, 60,000 pixels of each class were randomly selected from the training polygons. From the accuracy assessment, producer (PA) and user (UA) accuracies, and overall accuracy (OA) were calculated (Congalton, 1991; Olofsson et al., 2014). The time elapsed for classification was also recorded to analyze the viability of polarimetric process time.

\section{RESULTS}

For LEM, the best classification result was achieved just before the end of the soybean cycle (03-15-2018), corresponding to scenario 12 in BP, as can be observed in Figure 4a. Despite this, the results have started to stabilize in scenario 10 (Figure 4a), four images before the soybean cycle end, with overall accuracy (OA) around 79 82\% in both groups, BS and BP. At this time/scenario, the soybean was in the period between the maximum vegetative vigor and the senescence beginning. After that, scenario 11 to scenario 13 , the accuracy increase was small, but the processing time was considerably longer.
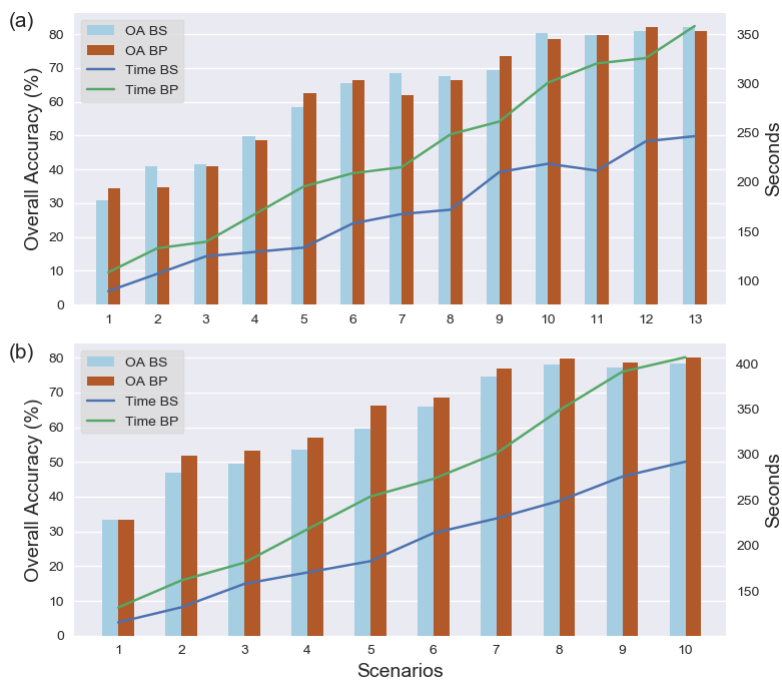

Figure 4. Overall Accuracy (OA) and processing time for LEM

(a) and Campo Verde (b) tests sites: BS (Backscattering coefficients $-\sigma^{0} \mathrm{VH}, \sigma^{0} \mathrm{VV}$, and $\sigma^{0} \mathrm{VH} / \sigma^{0} \mathrm{VV}$ ) and BP

(Backscattering coefficients + Polarimetric attributes $-\sigma^{0} \mathrm{VH}$, $\sigma^{0} \mathrm{VV}, \sigma^{0} \mathrm{VH} / \sigma^{0} \mathrm{VV}, \mathrm{H}$ and $\alpha$ ).

For Campo Verde, the better OA obtained, around 78 80\%, was achieved using the BP group, in the scenarios 8 and 10 (Figure $4 b$ ). However, the processing time for both scenarios was longer, $\sim 100$ seconds, when compared to the same scenario formed by BS. As in LEM, in Campo Verde, the OA also stabilized during the period of maximum vegetative vigor and the beginning of crop senescence.

In general, for the LEM test site, although the best accuracy was obtained from the BP group, it was almost equal to that obtained for the BS group. In Campo Verde, the result obtained with the BP group was about $2 \%$ higher than the one obtained from BS for the 12 scenarios analyzed (exception scenario 1). Also, the scenarios formed with the largest number of images did not present much higher classification results. In LEM, for the 11, 12 , and 13 scenarios, in the BS and BP groups, the OA was around $80 \%$, reaching $82 \%$ in the 12 BP scenario. The same happened to Campo Verde, where the BS and BP 8, 9, and 10 scenarios showed the OA $\sim 80 \%$ too.

In some cases, for LEM, during the soybean development period, the accuracy of the classification using the BS group overcame the result from BP. Moreover, the time taken to classify both datasets was longer for the BP group.

The UA and PA accuracies best scenario for LEM and Campo Verde are presented in Figures $4 \mathrm{a}$ and $4 \mathrm{~b}$, respectively. Soybean class obtained UA $>82 \%$, and PA $>87 \%$ in both test sites. On the other hand, Pasture obtained the lowest accuracy, with UA $\sim 20 \%$, and PA $\sim 64 \%$ for LEM, and, UA 27\%, and PA 52\% for Campo Verde. 

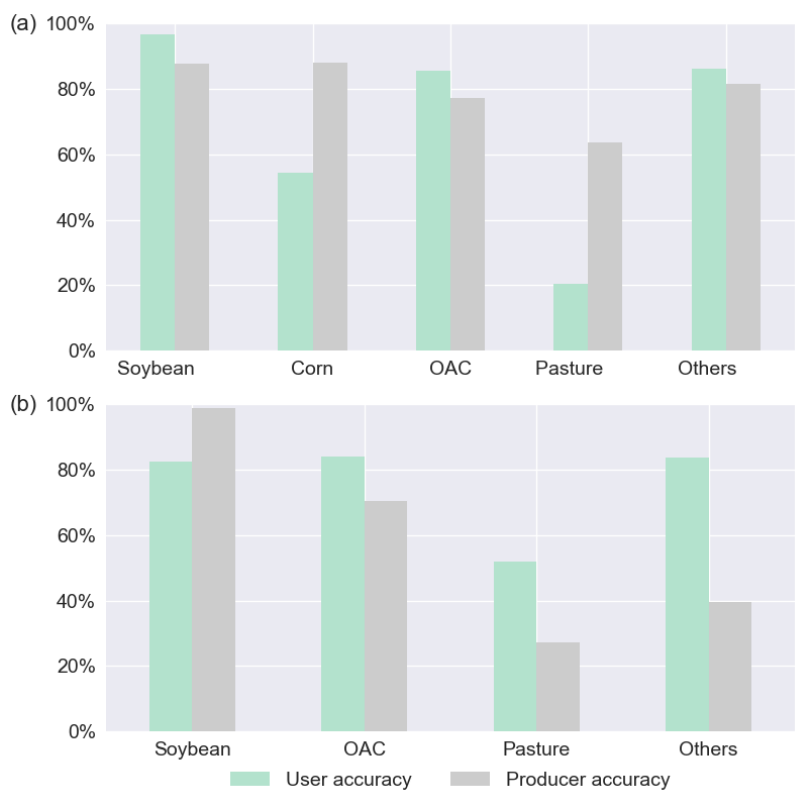

Figure 5. User (UA) and Producer (PA) accuracy for the best scenario results: (a) LEM: 03-15-2018 (scenario $12 \mathrm{BP}$ ); (b)

Campo Verde: 03-09-2016 (scenario 10 BP).

For LEM site, besides the lowest accuracy observed for Pasture class, $14 \%$ of the pixels of Others class were erroneously classified as Pasture. In Campo Verde, the biggest confusion also occurred with the Pasture class, $45 \%$ of the pixels were erroneously classified as Others, and $15 \%$ of the pixels Other class were erroneously classified as Pasture. Also, $10 \%$ of the Soybean pixels were misclassification with the Pasture.

Figure 6 shows the maps of the best classification results for the two test sites. It is possible to observe isolated classified pixels, this occurs mainly because of the effect of speckle, which was not reduced in the pre-processing step. The effect of speckle produces a grainy appearance in SAR images. This effect occurred more intensely in Campo Verde compared to the LEM.

\section{DISCUSSION}

The results show better classification accuracy for the combination of backscatter coefficients with metrics derived from polarimetric decomposition - BP group. In the LEM test site (Figure 4a), the difference between the BS and BP groups was inferior compared to Campo Verde (Figure 4b). The processing time was longer for the classification using all metrics (BP) in comparison to only using backscatter coefficients (BS), being a trade-off about increased accuracy (Figure 4).

In both test sites, classification accuracy was low at the beginning of the crop cycle. During this period, plants are beginning to emerge above the surface, and there is a greater influence of soil surface on the backscattering response, affecting the overall results of the classification.

However, during crop growth, the vegetation tends to attenuate soil backscatter, because the ears, leaves, and stems are developing. The backscatter at C-band is sensitive to changes in plant development (McNairn and Shang, 2016), so it is expected that the different scenarios, formed by multitemporal SAR images detect the changes in the crop's structure, and improve the separability in the classification. During the phenological development of crops, such as soybean and corn, there is a greater contribution, especially of cross-polarization $\mathrm{VH}$, of the ratio $\mathrm{VH} / \mathrm{VV}$, and $\mathrm{H}$ polarimetric attributes, that are more sensitive to volumetric scattering (Denise et al., 2019). The polarization VV demonstrates more sensitivity to vertical structures, like the stems of the plants.

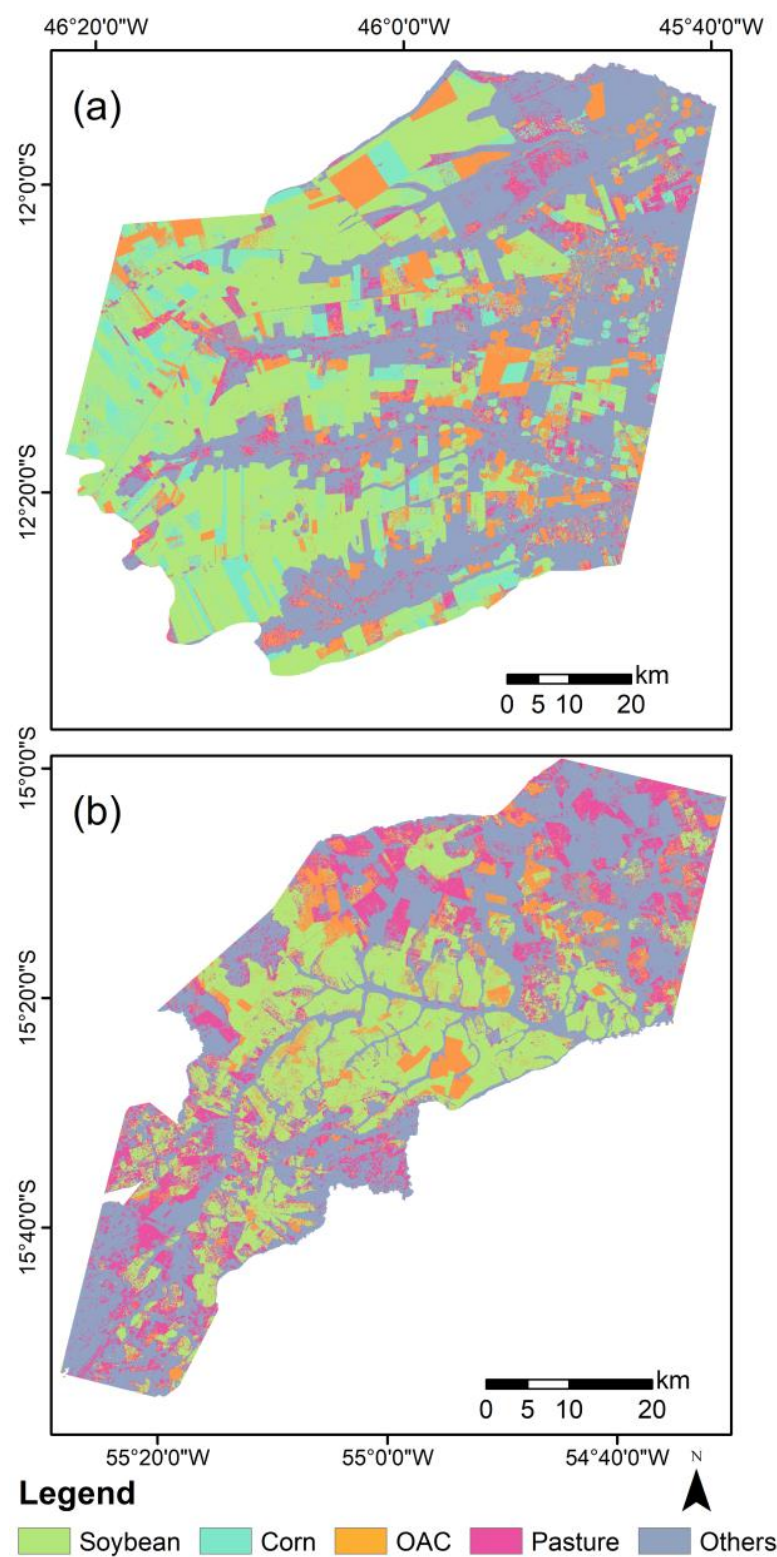

Figure 6. Maps for the best results of classification for LEM and Campo Verde test site: (a) LEM: 03-15-2018 (scenario 12 BP); (b) Campo Verde: 03-09-2016 (scenario 10 BP).

Oldoni et al. (2019b) demonstrated the greatest capabilities to accompany the growth of crops with the backscattering coefficients, $\sigma^{0} \mathrm{VV}$ and $\sigma^{0} \mathrm{VH}$. The authors observed that both coefficients have increased during the beginning of soybean growth. Furthermore, the polarimetric attributes $(H$ and $\alpha)$ demonstrated the potential for discrimination classes corn, soybean, and cotton in specific crop cycle periods.

Arias et al. (2020), used Sentinel-1 multitemporal images, in VH and $\mathrm{VV}$ polarizations, to classify crops. Both polarizations demonstrated sensitivity to many phenological events, as the 
structural characteristics of the canopy varied. The ratio (VH/VV) showed more sensitivity to vegetation growth, which allowed determining whether a field was vegetated or not but providing poor information about crop identification.

Sanches et al. (2018a) used the Sentinel-1 SAR image to provide the crop classification in LEM, using a different approach. They used one image per-month, between June-2017 and May-2018. According to these authors, the accuracy was also improved as more Sentinel-1 images were added. However, the maximum accuracy for them was obtained in November-2017 (OA near $85 \%$ ) and decrease with the image from January-2018 (OA under $50 \%$ ). Sanches et al. (2018b), used the backscatter coefficients of Sentinel-1, in VV and VV polarizations to classifying all classes of the Campo Verde Database. Their results showed an increase in accuracy from the beginning of the summer crop cycle. The overall accuracy stagnated after December when it came close to $65 \%$. A similar result was reported in this research when the classification overall accuracy stabilizing in midDecember in Campo Verde.

In this research, it was observed that the accuracy increases until the crops stabilize, about 3.5 months and 2.5 months after the average start of the cycle in LEM and Campo Verde, respectively. After the crop periods of stabilizing, it was observed in LEM, that the results of classifications remaining constant close to $80 \sim 82 \%$ overall accuracy (Figure $4 a$ ), and in Campo Verde, remaining constant close to $80 \%$ overall accuracy (Figure 4b).

This demonstrates the importance of acquiring multitemporal SAR images to maximize the accuracy gains of the results of the classification, especially of land use typologies that present a greater dynamic in space and time, such as crops. Tomppo et al., (2019) affirm that the multitemporal SAR image acquisition during the seed and reproductive phenology phases of the plant can improve the results accuracies of classifications of crops.

In general, the Soybean class obtained the best producer and user classification accuracies (Figure 5) after the moment when overall accuracy stabilized (scenarios 10 to 13 for LEM, and 7 to 10 for Campo Verde - Figure 4). The second best classification results were obtained for OAC class, with producer and user accuracy larger than $70 \%$.

On the other hand, the Pasture class had the worst producer and user accuracy (Figure 5). Its main misclassifications occurred with the Others class, wherein Cerrado is included in this class. Cerrado is also formed by natural pasture formations. These formations have a structure like the pasture used for cattle, which explains the confusion. Prudente et al. (2019b) also identified a similar problem. Another confusion erroneously classified that occurred was OAC with Soybean and Corn (Figure 5). The OAC class is formed by crops such as beans and sorghum, which have structures similar to soybeans and corn, respectively. This may explain the misclassifications among these classes.

Although the classification results of the BS and BP groups have shown similar discriminatory potential, it can be observed in Figure $4 \mathrm{~b}$, for the Campo Verde test site, that for some scenarios (2-5) the addition of information from the polarimetric attributes increased the general accuracy of the classifications. The addition of the signal phase information (complex data), possibly made it possible to separate the scattering mechanisms of different natures, which may have helped in the discrimination of the targets. In this way, it is possible to note that these parameters can be used for improving the accuracy of crop classification, although more studies are needed to understand the gain of each crop.

\section{CONCLUSIONS}

In LEM test site, the best results were equivalent with or without the addition of polarimetric metrics $(\mathrm{H}$ and $\alpha$ ) to the metrics obtained from backscatter coefficients $\left(\sigma^{0} \mathrm{VH}, \quad \sigma^{0} \mathrm{VV}\right.$, $\left.\sigma^{0} \mathrm{VH} / \sigma^{0} \mathrm{VV}\right)$. In the Campo Verde test site, the addition of polarimetric metrics showed an overall accuracy of around $2 \%$ higher than the non-use of polarimetric metrics, except for the first scenario.

The addition of new images over the crop development period increases overall accuracy, stabilizing from mid-February in LEM, and mid-December in Campo Verde. After these periods, the gain in accuracy is small with the addition of new images. For future works, it is recommended to evaluate the use of segmentation or the combination with data obtained by optical sensors to improve the results. Besides, it is also recommended to carry out data mining to assess the performance of each polarimetric attribute and backscatter coefficient into each class, to form optimal sets that allow for better discrimination of different classes of land use and land cover.

\section{ACKNOWLEDGEMENTS}

This study was financed in part by the Coordenação de Aperfeiçoamento de Pessoal de Nível Superior - Brasil (CAPES) - Finance Code 001 and the National Council for Scientific and Technological Development (CNPq).

\section{REFERENCES}

Arias, M., Campo-Bescós, M. A., Álvarez-Mozos, J., 2020. Crop Classification Based on Temporal Signatures of Sentinel-1 Observations over Navarre Province, Spain. Remote Sens. 12, 278. https://doi.org/10.3390/rs12020278

Atzberger, C., 2013. Advances in Remote Sensing of Agriculture: Context Description, Existing Operational Monitoring Systems and Major Information Needs. Remote Sens. 5, 949-981. https://doi.org/10.3390/rs5020949

Breiman, L., 2001. Random Forests. Mach. Learn. 45, 5-32. https://doi.org/10.1023/A:1010933404324

Cloude, S.R., Pottier, E., 1996. A review of target decomposition theorems in radar polarimetry. IEEE Trans. Geosci. Remote Sens. 34, 498-518. https://doi.org/10.1109/36.485127

Congalton, R.G., 1991. A Review of Assessing the Accuracy of Classification of Remotely Sensed Data A Review of Assessing the Accuracy of Classifications of Remotely Sensed Data. Remote Sens. Environ. 4257, 34-46. https://doi.org/10.1016/0034-4257(91)90048-B

Denize, J., Hubert-Moy, L., Pottier, E., 2019. Polarimetric SAR Time-Series for Identification of Winter Land Use. Sensors 2, 119. https://doi.org/10.3390/s19245574

Du, P., Samat, A., Waske, B., Liu, S., Li, Z., 2015. Random Forest and Rotation Forest for fully polarized SAR image classification using polarimetric and spatial features. ISPRS J. 
Photogramm. Remote Sens. 105, 38-53. https://doi.org/10.1016/j.isprsjprs.2015.03.002

Eberhardt, I.D.R., Schultz, B., Rizzi, R., Sanches, I.D.A., Formaggio, A.R., Atzberger, C., Mello, M.P., Immitzer, M., Trabaquini, K., Foschiera, W., Luiz, A.J.B., 2016. Cloud cover assessment for operational crop monitoring systems in tropical areas. Remote Sens. 8, 1-14. https://doi.org/10.3390/rs8030219

Evans, T.L., Costa, M., 2013. Landcover classification of the Lower Nhecolândia subregion of the Brazilian Pantanal Wetlands using ALOS/PALSAR, RADARSAT-2 and ENVISAT/ASAR imagery. Remote Sens. Environ. 128, 118 137. https://doi.org/10.1016/j.rse.2012.09.022

FAOSTAT, 2020. FAO statistical database. Food Agric. Organ. United Nations - Stat. Div. FAOSTAT. URL http://www.fao.org/faostat/en/\#data/QC (accessed 1.27.20).

Furtado, L.F. de A., Silva, T.S.F., Novo, E.M.L. de M., 2016. Dual-season and full-polarimetric C band SAR assessment for vegetation mapping in the Amazon várzea wetlands. Remote Sens. Environ. 174, 212-222. https://doi.org/10.1016/j.rse.2015.12.013

Harfenmeister, K., Spengler, D., Weltzien, C., 2019. Analyzing Temporal and Spatial Characteristics of Crop Parameters Using Sentinel-1 Backscatter Data. Remote Sens. 11, 1569. https://doi.org/10.3390/rs11131569

Hu, J., Ghamisi, P., Zhu, X., 2018. Feature Extraction and Selection of Sentinel-1 Dual-Pol Data for Global-Scale Local Climate Zone Classification. ISPRS Int. J. Geo-Information 7, 379. https://doi.org/10.3390/ijgi7090379

IBGE, Instituto Brasileiro de Geografia e Estatística, 2017. Luis Eduardo Magalhães. Prod. Interno Bruto dos Municípios. URL https://cidades.ibge.gov.br/brasil/ba/luis-eduardo-

magalhaes/pesquisa/38/46996?tipo $=$ ranking $\&$ indicador $=47006$ (accessed 2.3.19).

Kussul, N., Lemoine, G., Gallego, F.J., Skakun, S. V., Lavreniuk, M., Shelestov, A.Y., 2016. Parcel-Based Crop Classification in Ukraine Using Landsat-8 Data and Sentinel-1A Data. IEEE J. Sel. Top. Appl. Earth Obs. Remote Sens. 9, 2500-2508. https://doi.org/10.1109/JSTARS.2016.2560141

Lu, D., Li, G., Moran, E., Dutra, L., Batistella, M., 2011. A Comparison of Multisensor Integration Methods for Land Cover Classification in the Brazilian Amazon. GIScience Remote Sens. 48, 345-370. https://doi.org/10.2747/1548-1603.48.3.345

McNairn, H., Brisco, B., 2004. The application of C-band polarimetric SAR for agriculture: a review. Can. J. Remote Sens. 30, 525-542. https://doi.org/10.5589/m03-069

McNairn, H., Kross, A., Lapen, D., Caves, R., Shang, J., 2014 Early season monitoring of corn and soybeans with TerraSAR-X and RADARSAT-2. Int. J. Appl. Earth Obs. Geoinf. 28, 252259. https://doi.org/10.1016/j.jag.2013.12.015

McNairn, H., Shang, J., 2016. Multitemporal Remote Sensing, Springer. ed, Springer, Remote Sensing and Digital Image Processing. Springer International Publishing, Cham, Switzerland,. https://doi.org/10.1007/978-3-319-47037-5
Oldoni, L.V., Cattani, C.E.V., Mercante, E., Johann, J.A., Antunes, J.F.G., Almeida, L., 2019. Annual cropland mapping using data mining and OLI Landsat-8. Rev. Bras. Eng. Agrícola e Ambient. 23, 952-958. https://doi.org/10.1590/18071929/agriambi.v23n12p952-958

Olofsson, P., Foody, G.M., Herold, M., Stehman, S. V., Woodcock, C.E., Wulder, M.A., 2014. Good practices for estimating area and assessing accuracy of land change. Remote Sens. Environ. 148, 42-57. https://doi.org/10.1016/j.rse.2014.02.015

Pal, M., 2005. Random forest classifier for remote sensing classification. Int. J. Remote Sens. 26, 217-222. https://doi.org/10.1080/01431160412331269698

Pedregosa, F., Varoquaux, G., Gramfort, A., Michel, V., Thirion, B., Grisel, O., Blondel, M., Prettenhofer, P., Weiss, R., Dubourg, V., Vanderplas, J., Passos, A., Cournapeau, D., Brucher, M., Perrot, M., Duchesnay, É., 2011. Scikit-learn: Machine Learning in Python. J. Mach. Learn. Res. 12, 2825-2830. https://doi.org/10.1007/s13398-014-0173-7.2

Peel, M.C., Finlayson, B.L., McMahon, T.A., 2007. Updated world map of the Koppen-Geiger climate classificatio. Hydrol. Earth Syst. Sci. 11, 1633-1644.

Prudente, V.H.R., Oldoni, L.V., Vieira, D.C., Cattani, C.E. V., Sanches, I.D., 2019a. Relationship between SAR/Sentinel-1 polarimetric and interferometric data with biophysical parameters of agricultural crops. ISPRS - Int. Arch. Photogramm. Remote Sens. Spat. Inf. Sci. XLII-3/W6, 599-607. https://doi.org/10.5194/isprs-archives-XLII-3-W6-599-2019

Prudente, V.H.R., Vieira, D.C., Montibeller, B., Oldoni, L.V., Sanches, I.D., Adami, M., 2019b. Utilização de dados SAR na classificação de espécies agrícolas de primeira e segunda safra, in: Anais Do XIX Simpósio Brasileiro de Sensoriamento Remoto. INPE, Santos, pp. 1643-1647.

Rodriguez-Galiano, V.F., Ghimire, B., Rogan, J., Chica-Olmo, M., Rigol-Sanchez, J.P., 2012. An assessment of the effectiveness of a random forest classifier for land-cover classification. ISPRS J. Photogramm. Remote Sens. 67, 93-104. https://doi.org/10.1016/j.isprsjprs.2011.11.002

Sanches, I.D., Feitosa, R.Q., Achanccaray, P., Montibeller, B., Luiz, A.J.B., Soares, M.D., Prudente, V.H.R., Maurano, L.E.P., Janeiro, R. De, 2018a. LEM benchmark database for tropical agricultural remote sensing application, in: ISPRS TC I Midterm Symposium Innovative Sensing - From Sensors to Methods and Applications. ISPRS, Karlsruhe, pp. 1-6.

Sanches, I.D., Feitosa, R.Q., Diaz, P.M.A., Soares, M.D., Luiz, A.J.B., Schultz, B., Maurano, L.E.P., 2018b. Campo Verde Database: Seeking to Improve Agricultural Remote Sensing of Tropical Areas. IEEE Geosci. Remote Sens. Lett. 15, 369-373. https://doi.org/10.1109/LGRS.2017.2789120

Steele-Dunne, S.C., McNairn, H., Monsivais-Huertero, A., Judge, J., Liu, P.-W., Papathanassiou, K., 2017. Radar Remote Sensing of Agricultural Canopies: A Review. IEEE J. Sel. Top. Appl. Earth Obs. Remote Sens. 10, 2249-2273. https://doi.org/10.1109/JSTARS.2016.2639043

Tomppo, E., Antropov, O., Praks, J., 2019. Cropland Classification Using Sentinel-1 Time Series: Methodological 
Performance and Prediction Uncertainty Assessment. Remote Sens. 11, 2480. https://doi.org/10.3390/rs11212480

Ulaby, Fawwaz, T., Elachi, C., 1990. Radar polarimetry for geoscience applications. Norwood, MA : Artech House.

Veloso, A., Mermoz, S., Bouvet, A., Le Toan, T., Planells, M. Dejoux, J.F., Ceschia, E., 2017. Understanding the temporal behavior of crops using Sentinel-1 and Sentinel-2-like data for agricultural applications. Remote Sens. Environ. 199, 415-426. https://doi.org/10.1016/j.rse.2017.07.015

Whitcraft, A.K., Becker-Reshef, I., Justice, C., 2015a. A Framework for Defining Spatially Explicit Earth Observation Requirements for a Global Agricultural Monitoring Initiative (GEOGLAM). Remote Sens. 7, 1461-1481. https://doi.org/10.3390/rs70201461

Whitcraft, A.K., Vermote, E.F., Becker-Reshef, I., Justice, C.O., 2015b. Cloud cover throughout the agricultural growing season: Impacts on passive optical earth observations. Remote Sens. Environ. 156, 438-447. https://doi.org/10.1016/j.rse.2014.10.009

Wulder, M.A., Hilker, T., White, J.C., Coops, N.C., Masek, J.G., Pflugmacher, D., Crevier, Y., 2015. Virtual constellations for global terrestrial monitoring. Remote Sens. Environ. 170, 62-76. https://doi.org/10.1016/j.rse.2015.09.001

You, N., Dong, J., 2020. Examining earliest identifiable timing of crops using all available Sentinel 1/2 imagery and Google Earth Engine. ISPRS J. Photogramm. Remote Sens. 161, 109123. https://doi.org/10.1016/j.isprsjprs.2020.01.001 